\title{
Predictors of Health-related Quality of Life in Patients with Non-specific Low Back Pain
}

\author{
Ogunlana M.O., ${ }^{1}$ Odunaiya N.A., ${ }^{2}$ Dairo M.D., ${ }^{3}$ Ihekuna O. ${ }^{1}$ \\ ${ }^{1}$ Department of Physiotherapy, Federal Medical Centre Abeokuta, Ogun State, Nigeria \\ ${ }^{2}$ Department of Physiotherapy, University of Ibadan, Oyo State, Nigeria \\ ${ }^{3}$ Department of Epidemiology, University of Ibadan, Oyo State, Nigeria \\ Correspondence \\ O.M. Ogunlana, Department of Physiotherapy, Federal Medical Centre Abeokuta, Ogun State, Nigeria
}

\begin{abstract}
SUMMARY
This study examined the health-related quality of life (HRQOL) of patients with non-specific LBP and its predictors at a physiotherapy outpatient clinic in a tertiary health institution located in Abeokuta, southwestern Nigeria.

The subjects were asked to complete the SF 36, Oswestry disability questionnaire (ODQ) and Quadruple Visual Analogue scale (QVAS). Socio-demographic and LBP-related information were also obtained using a speciallydesigned proforma. Multiple linear regression analysis was used to examine the influence of the sociodemographic and LBP-related variables on the HRQOL of the respondents.

Absence of numbness in the lower limb $(p=0.043)$ and being a female were significant positive predictors of total quality of life $($ TQOL) score. Increasing age $(p=0.005)$, pain $(p=0.038)$ and level of disability $(p<0.0001)$ were significant negative predictors of TQOL score.

Evidence from this study shows that increasing age and level of disability adversely affected the HRQOL of LBP patients more than just the pain (which affects the physical component of HRQOL more). Female patients reported better HRQOL. The presence of numbness in the lower limb is the major symptom that significantly affects all the components of HRQOL adversely. The predictor of HRQOL in this population is not different from that in Asian and Caucasian populations.
\end{abstract}

KEYWORDS: Non-specific low back pain, health-related quality of life, predictor, disability.

\section{INTRODUCTION}

Low back pain (LBP) affects about $80 \%$ of the population at some time in their lives (Andersson, 1999), and is one of the most frequent reasons for consulting a primary care physician and for taking time off work (Frymoyer, 1988). The patient with LBP not only suffers from physical discomfort, but also from functional limitation, which might cause disability and interfere with their quality of life (Horng et al, 2005). LBP can interfere with basic activities of daily living like walking and dressing, and many workrelated functions. It might seem obvious that pain determines disability in patients with LBP, but some studies have shown that the intensity of pain and the degree of disability do not correlate well and are associated with different risk factors (Allan \& Waddell, 1989; Nachemson,1992; Pincus et al, 2002; Kovacs et al, 2004). Biomechanical factors influence pain, but psychosocial factors have more influence on the development and duration of disability (Kovacs et al, 2004). For this reason, a biopsychosocial analysis of LBP has been suggested (Waddell, 1992), necessitating the evaluation of healthrelated quality of life (HRQOL) in patients with LBP.

The measurement of HRQOL has been widely used to evaluate the broad impact of various diseases on patients 
and the effectiveness of interventions (Testa and Simonson, 1996). In the context of LBP, it may be useful in understanding the natural history of the condition, which may help improve the clinical management of patients by extending the assessment process beyond the traditional, and clearly insufficient, clinical and functional disability variables (Coste et al, 2004). Biological and psychosocial factors have been reported to affect the HRQOL of patients with LBP (Coste et al, 2004). Also, it has been reported that HRQOL in patients with LBP is more dependent on functional status and psychological factors, than on physical impairment (Horng et al, 2005). Determinants of HRQOL in patients with LBP have been well-documented in Caucasian and Asian populations (Horng et al, 2005; Patrick et al, 1995; Nickel et al, 2001). It will be of benefit to know the determinants of HRQOL in a typical African population. Knowledge of the HRQOL may be useful in planning therapeutic interventions that will ensure desirable HRQOL and not just pain relief.

\section{METHODS}

\section{Study Population and Design}

This study was a descriptive, cross-sectional survey, and it documented the HRQOL of patients being managed for non-specific LBP at the physiotherapy outpatient clinic of the Federal Medical Centre, Abeokuta. The participants were all consecutive patients who had been diagnosed with LBP of a non-specific aetiology and receiving treatment at the physiotherapy outpatient clinic. The clinic runs four times a week, with an average attendance of 20 patients weekly. All non-specific LBP patients seen at the clinic during the period of the study (three and a half years) who met the inclusion criteria were invited to participate in the study. The sample size was 169 and was determined using data from a previous study (Coste et al, 2004), where the SD for HRQOL scores in a population of LBP patients was 27.6 , and assuming an alpha of 0.05 and a beta of 0.10 , and a 2-tailed test with a difference of a quarter of the SD. Participation in the study was totally voluntary. The subjects were asked to complete the questionnaires by interview, after their informed consent had been obtained in writing. Ethical approval for the study was given by the Federal Medical Centre Health Research Committee. The socio-demographic factors included in this study were gender, age, ethnic group, marital status, religious affiliation, educational status, social class and average monthly income. Marital status was categorized as married, single or widowed. Educational status was divided into four levels: no education, primary, secondary and tertiary education. Social class was divided into three categories: blue collar, white collar and self-employed (Bardage and Isacson, 2001). Average monthly income was reported as low (less than $\$ 25,000$ ), average ( $\$ 25000$ to $\$ 100,000$ ) and high (greater than $\$ 100,000$ ). The clinical and disease characteristics included in this study were prevalence of symptoms which included numbness, paraesthesia, weakness, urinary incontinence/retention and faecal incontinence/constipation.

\section{Measurement of Impairment, Disability and HRQOL}

The quadruple visual analog scale (Von Korff et al, 1993) was used to assess pain intensity. This scale measures pain intensity at four levels; 'pain right now', 'average pain', 'best pain' and 'worst pain'. It consists of four visual analog scales. Each scale consists of a $10 \mathrm{~cm}$ long horizontal line, the ends of which are marked with the extreme states of the items being measured. It has been widely-used with good validity and reliability (Von Korff et al, 1993). In this study, the patients were asked to mark their pain intensity on the quadruple visual analog scale.

The Oswestry disability questionnaire (ODQ) was used as an LBP functional assessment tool. It has been shown to be a valid indicator of disability in patients with LBP. It is divided into ten sections, with six levels each, assessing the limitation of various activities of daily living (Fairbank and Pynscent, 2000; Davidson and Keating, 2002). The range of possible values is from 0 (the best health state) to 100 (the worst health state). Scoring of this questionnaire was done to compute the disability index percent (DIP). For each section of the questionnaire, the total possible score was five. The first statement was scored 0 and consecutive statements were scored 1 to 5 . The total score was divided by the total possible score and expressed in percentage to produce the disability index percent. The DIP score can be interpreted as: 0 - 20\% (minimal disability), $21-40 \%$ (moderate disability), $41-60 \%$ (severe disability), 61 $80 \%$ (crippled) and $81-100 \%$ (bed-bound or exaggerated symptoms). The ODQ was administered once by interview to the participants. The estimated duration for administration of the instrument was ten minutes.

The Short Form-36 (SF-36) Health Survey, version 2.0 (Ware, 2000) was used to assess HRQOL. Its validity, reproducibility and responsiveness to change over time have been well-documented (Ware, 2000). It has 36 items that 
measure the health concepts of physical functioning, role limitations due to physical health problems, body pain, general health, vitality, social function, role limitations due to emotional problems, and mental health. It also contains a single item that examines change in health over time. Summary measures of physical health (Physical Component Summary [PCS]), mental health (Mental Component Summary [MCS]) and total QOL score (TQOL) were derived from the completed questionnaire. The SF-36 was administered once by interview to the participants. The estimated duration for administration of this instrument was 15 minutes. Relevant clinical information about the respondents was obtained from their hospital case files.

\section{RESULTS}

Two hundred and twenty patients with LBP were enrolled in this study out of which 204 participated, giving a response rate of $92.7 \%$. Sixteen of the patients declined to participate for personal reasons. The mean age of the participants was $50.63 \pm 13.47$ years. Forty nine percent of the participants were male, $57.1 \%$ had tertiary education and $80.4 \%$ were presently married. A majority of the participants were Yoruba (92\%) and $42.6 \%$ of the respondents were Christians. About two thirds (64.4\%) of the respondents were white collar workers, with $43.1 \%$ earning less than $\$ 25,000$ per month (low income group). All the participants had LBP, with weakness of lower limb being the most prevalent symptom $(21.6 \%)$ after pain. The mean duration of LBP was 2 years, with a range of three months to ten years. Table 1 shows the respondents sociodemographic and clinical characteristics. The mean Quadruple Visual Analogue scale (QVAS) of the respondents was $7.31 \pm 1.93$, with a range of 3 to 10 . The level of disability measured using the Oswestry disability questionnaire revealed that almost half of the respondents (47.9\%) had severe disability as a result of LBP. Also, using the SF 36 scale, the mean TQOL score was $57.36 \pm$ 17.40. Table 2 shows the respondents' mean scores on QVAS, ODQ and SF 36.

\section{Bivariate Analyses}

\section{Physical component summary (PCS)}

The influence of socio-demographic and clinical variables on the physical component summary score of HRQOL is presented in table 3 . The female respondents had a significantly better PCS score $(p=0.004)$. There was a reduction in PCS scores with increase in age $(\mathrm{p}<0.0001)$.
Respondents that were Yoruba ( $\mathrm{p}<0.0001)$, with higher educational status $(p=0.024)$, who did not present with numbness in the lower limbs $(\mathrm{p}=0.009)$ had a higher PCS score. The PCS score decreased as the level of disability ( $p$ $<0.0001)$ and duration of LBP $(\mathrm{p}=0.002)$ increased.

Table 1. Socio-demographic and clinical characteristics of respondents

\begin{tabular}{|c|c|c|c|}
\hline Variable & Characteristics & Frequency & Percentage \\
\hline \multirow[t]{2}{*}{ Gender } & Male & 100 & 49.0 \\
\hline & Female & 104 & 51.0 \\
\hline \multirow[t]{5}{*}{ Age group } & $20-29$ & 4 & 2.0 \\
\hline & $30-39$ & 40 & 19.6 \\
\hline & $40-49$ & 60 & 29.4 \\
\hline & $50-59$ & 40 & 19.6 \\
\hline & $\geq 60$ & 60 & 29.4 \\
\hline \multirow[t]{2}{*}{ Tribe } & Yoruba & 188 & 92.0 \\
\hline & Non-Yoruba & 16 & 8.0 \\
\hline \multirow[t]{2}{*}{ Religion } & Christianity & 87 & 42.6 \\
\hline & Islam & 117 & 57.4 \\
\hline \multirow{4}{*}{$\begin{array}{l}\text { Educational } \\
\text { status }\end{array}$} & No education & 8 & 4.1 \\
\hline & Primary & 38 & 18.4 \\
\hline & Secondary & 42 & 20.4 \\
\hline & Tertiary & 116 & 57.1 \\
\hline \multirow[t]{3}{*}{ Social class } & White collar & 131 & 64.4 \\
\hline & Blue collar & 18 & 8.9 \\
\hline & Self employed & 55 & 26.7 \\
\hline \multirow[t]{3}{*}{ Income group } & Low income & 88 & 43.1 \\
\hline & Middle income & 83 & 40.7 \\
\hline & High income & 32 & 15.7 \\
\hline \multirow{4}{*}{$\begin{array}{l}\text { Prevalence of } \\
\text { symptoms }\end{array}$} & Numbness & 36 & 17.6 \\
\hline & Paraesthesia & 28 & 13.7 \\
\hline & Lower limb weakness & 44 & 21.6 \\
\hline & Incontinence & 0 & 0.0 \\
\hline
\end{tabular}

Table 2. LBP impairment, disability and HRQOL measurement

\begin{tabular}{llll}
\hline Variable & Characteristics & $\begin{array}{l}\text { Mean and SD/ } \\
\text { Frequency }\end{array}$ & $\begin{array}{l}\text { Range/ } \\
\text { Percentage }\end{array}$ \\
\hline Pain & Present VAS & $4.89 \pm 2.31$ & $0-10$ \\
measurement & Average VAS & $4.48 \pm 1.99$ & $0-9$ \\
& Best VAS & $3.52 \pm 2.63$ & $0-10$ \\
& Worst VAS & $7.31 \pm 1.93$ & $3-10$ \\
Disability & Minimal disability & 9 & 4.2 \\
measurement & Moderate disability & 38 & 18.8 \\
& Severe disability & 98 & 47.9 \\
& Crippled & 55 & 27.1 \\
& Bedridden & 4 & 2.1 \\
& Physical component & $52.92 \pm 18.81$ & $13.75-90$ \\
HRQOL & Mental component & $61.84 \pm 19.44$ & $21.96-99$ \\
measurement & TQOL & $57.36 \pm 17.40$ & $25.56-90$ \\
\hline
\end{tabular}


Table 3. Influence of physical component summary score of HRQOL on socio-demographic and clinical variables

\begin{tabular}{|c|c|c|c|c|}
\hline Variable & Sub - group & Mean $\pm S D$ & $\begin{array}{l}\text { Test } \\
\text { statistic }\end{array}$ & P-value \\
\hline \multirow[t]{2}{*}{ Gender } & Male & $49.0 \pm 18.4$ & -2.9 & 0.004 \\
\hline & Female & $56.8 \pm 18.5$ & & \\
\hline \multirow[t]{5}{*}{ Age group } & $20-29$ & $67.5 \pm 0.0$ & 6.6 & 0.00 \\
\hline & $30-39$ & $61.9 \pm 2.8$ & & \\
\hline & $40-49$ & $55.2 \pm 2.5$ & & \\
\hline & $50-59$ & $42.1 \pm 2.0$ & & \\
\hline & $\geq 60$ & $50.0 \pm 2.6$ & & \\
\hline \multirow{4}{*}{$\begin{array}{l}\text { Duration of } \\
\text { LBP }\end{array}$} & LBP $<1$ year & $58.61 \pm 16.0$ & 3.21 & 0.002 \\
\hline & & 8 & & \\
\hline & LBP > 1year & $49.44 \pm 19.9$ & & \\
\hline & & 8 & & \\
\hline \multirow[t]{2}{*}{ Tribe } & Yoruba & $52.7 \pm 17.9$ & 5.5 & 0.00 \\
\hline & Non-Yoruba & $35.2 \pm 9.9$ & & \\
\hline \multirow[t]{2}{*}{ Religion } & Christianity & $54.4 \pm 20.2$ & 1.4 & 0.18 \\
\hline & Islam & $50.8 \pm 16.7$ & & \\
\hline \multirow{4}{*}{$\begin{array}{l}\text { Educational } \\
\text { status }\end{array}$} & No education & $41.3 \pm 4.0$ & 3.2 & 0.024 \\
\hline & Primary & $45.7 \pm 22.1$ & & \\
\hline & Secondary & $57.3 \pm 19.6$ & & \\
\hline & Tertiary & $53.5 \pm 17.8$ & & \\
\hline \multirow[t]{3}{*}{ Social class } & White collar & $52.7 \pm 16.4$ & 0.533 & 0.588 \\
\hline & Blue collar & $57.8 \pm 22.1$ & & \\
\hline & Self employed & $52.7 \pm 23.3$ & & \\
\hline Income & Low income & $53.8 \pm 19.7$ & 0.028 & 0.972 \\
\hline \multirow[t]{2}{*}{ group } & Middle income & $54.1 \pm 17.8$ & & \\
\hline & High income & $53.1 \pm 20.1$ & & \\
\hline \multirow[t]{2}{*}{ Numbness } & Present & $45.7 \pm 17.5$ & -2.71 & 0.009 \\
\hline & Absent & $54.6 \pm 18.8$ & & \\
\hline \multirow[t]{2}{*}{ Paraesthesia } & Present & $53.4 \pm 19.9$ & 0.156 & 0.876 \\
\hline & Absent & $52.8 \pm 19.2$ & & \\
\hline \multirow{2}{*}{$\begin{array}{l}\text { Lower limb } \\
\text { weakness }\end{array}$} & Present & $51.4 \pm 18.5$ & -62.4 & 0.572 \\
\hline & Absent & $53.3 \pm 18,9$ & & \\
\hline \multirow[t]{5}{*}{ Disability } & $\begin{array}{l}\text { Minimal } \\
\text { disability }\end{array}$ & $69.4 \pm 1.3$ & 30.3 & 0.000 \\
\hline & $\begin{array}{l}\text { Moderate } \\
\text { disability }\end{array}$ & $71.9 \pm 14.0$ & & \\
\hline & $\begin{array}{l}\text { Severe } \\
\text { disability }\end{array}$ & $54.8 \pm 15.7$ & & \\
\hline & Crippled & $39.9 \pm 12.9$ & & \\
\hline & Bedridden & $32.5 \pm 0.0$ & & \\
\hline
\end{tabular}

\section{Mental component summary (MCS)}

The influence of socio-demographic and clinical variables on the mental component summary score of HRQOL is presented in table 4 . The MCS scores were significantly different among the age groups $(\mathrm{p}<0.0001)$, with respondents in the 50-59 years age group having the lowest MCS score. Respondents that were Yoruba $(\mathrm{p}<0.0001)$, who do not present with numbness in the lower limb $(\mathrm{p}<0.0001)$ had significantly higher MCS scores.
The MCS scores were significantly different among respondents of different educational status ( $p<0.0001$ ), with respondents who did not have any formal education having the lowest MCS scores. The white collar ( $\mathrm{p}=$ $0.005)$ and middle income earning $(\mathrm{p}=0.038)$ respondents had significantly low MCS scores. There was a decrease in the MCS score as the level of disability increased ( $p<$ $0.0001)$.

Table 4. Influence of mental component summary score of HRQOL on socio-demographic and clinical variables

\begin{tabular}{|c|c|c|c|c|}
\hline Variable & Sub - group & Mean $\pm S D$ & $\begin{array}{l}\text { Test } \\
\text { statistic }\end{array}$ & P-value \\
\hline \multirow[t]{2}{*}{ Gender } & Male & $61.5 \pm 16.9$ & -0.211 & 0.833 \\
\hline & Female & $62.1 \pm 21.8$ & & \\
\hline \multirow[t]{5}{*}{ Age group } & $20-29$ & $59.4 \pm 0.00$ & 5.33 & 0.000 \\
\hline & $30-39$ & $63.5 \pm 14.6$ & & \\
\hline & $40-49$ & $68.7 \pm 17.9$ & & \\
\hline & $50-59$ & $49.8 \pm 16.1$ & & \\
\hline & $\geq 60$ & $60.5 \pm 22.6$ & & \\
\hline \multirow{2}{*}{$\begin{array}{l}\text { Duration of } \\
\text { LBP }\end{array}$} & LBP $<1$ year & $62.38 \pm 18.98$ & 0.87 & 0.384 \\
\hline & LBP $>1$ year & $59.79 \pm 19.38$ & & \\
\hline \multirow[t]{2}{*}{ Tribe } & Yoruba & $62.0 \pm 19.4$ & 2.86 & 0.005 \\
\hline & Non-Yoruba & $45.9 \pm 7.9$ & & \\
\hline \multirow[t]{2}{*}{ Religion } & Christianity & $63.2 \pm 20.9$ & 1.22 & 0.223 \\
\hline & Islam & $59.9 \pm 16.9$ & & \\
\hline \multirow{4}{*}{$\begin{array}{l}\text { Educational } \\
\text { status }\end{array}$} & No education & $45.4 \pm 14.9$ & 7.24 & 0.000 \\
\hline & Primary & $52.5 \pm 18.3$ & & \\
\hline & Secondary & $70.5 \pm 20.6$ & & \\
\hline & Tertiary & $62.3 \pm 18.4$ & & \\
\hline \multirow[t]{3}{*}{ Social class } & White collar & $60.2 \pm 18.4$ & 5.4 & 0.005 \\
\hline & Blue collar & $76.1 \pm 17.0$ & & \\
\hline & Self employed & $65.1 \pm 20.7$ & & \\
\hline \multirow[t]{3}{*}{ Income group } & Low income & $66.3 \pm 22.3$ & 3.3 & 0.038 \\
\hline & Middle income & $58.5 \pm 17.9$ & & \\
\hline & High income & $66.4 \pm 11.9$ & & \\
\hline \multirow[t]{2}{*}{ Numbness } & Present & $52.6 \pm 15.9$ & -3.692 & 0.000 \\
\hline & Absent & $63.9 \pm 19.6$ & & \\
\hline \multirow[t]{2}{*}{ Paraesthesia } & Present & $61.6 \pm 23.8$ & -0.061 & 0.952 \\
\hline & Absent & $61.9 \pm 18.7$ & & \\
\hline \multirow{2}{*}{$\begin{array}{l}\text { Lower limb } \\
\text { weakness }\end{array}$} & Present & $60.2 \pm 20.6$ & -0.580 & 0.64 \\
\hline & Absent & $62.3 \pm 19.2$ & & \\
\hline \multirow[t]{8}{*}{ Disability } & Minimal & $82.3 \pm 5.6$ & 24.2 & 0.000 \\
\hline & Disability & & & \\
\hline & Moderate & $80.4 \pm 14.6$ & & \\
\hline & Disability & & & \\
\hline & Severe & $61.0 \pm 18.0$ & & \\
\hline & Disability & & & \\
\hline & Crippled & $53.7 \pm 13.5$ & & \\
\hline & Bedridden & $21.9 \pm 0.00$ & & \\
\hline
\end{tabular}


Predictors of Health-related Quality of Life in Patients with Non-specific Low Back Pain

\section{Total quality of life (TQOL)}

The influence of socio-demographic and clinical variables on the total quality of life score is presented in table 5 .

Table 5. Influence of TQOL score of HRQOL on sociodemographic and clinical variables

\begin{tabular}{|c|c|c|c|c|}
\hline Variable & Sub group & Mean $\pm S D$ & $\begin{array}{l}\text { Test } \\
\text { Statistic }\end{array}$ & P-value \\
\hline \multirow[t]{2}{*}{ Gender } & Male & $55.2 \pm 15.9$ & -1.697 & 0.091 \\
\hline & Female & $59.5 \pm 18.9$ & & \\
\hline \multirow[t]{5}{*}{ Age group } & $20-29$ & $63.4 \pm 0.0$ & 6.244 & 0.000 \\
\hline & $30-39$ & $62.8 \pm 14.4$ & & \\
\hline & $40-49$ & $61.9 \pm 17.1$ & & \\
\hline & $50-59$ & $45.9 \pm 10.3$ & & \\
\hline & $\geq 60$ & $55.3 \pm 19.8$ & & \\
\hline \multirow{2}{*}{$\begin{array}{l}\text { Duration of } \\
\text { LBP }\end{array}$} & LBP $<1$ year & $60.49 \pm 15.72$ & 2.23 & 0.027 \\
\hline & LBP > 1year & $54.59 \pm 18.12$ & & \\
\hline \multirow[t]{2}{*}{ Tribe } & Yoruba & $57.3 \pm 16.9$ & 12.5 & 0.000 \\
\hline & Non - Yoruba & $40.5 \pm 1.3$ & & \\
\hline \multirow[t]{2}{*}{ Religion } & Christianity & $58.8 \pm 18.4$ & 1.425 & 0.156 \\
\hline & Islam & $55.3 \pm 15.7$ & & \\
\hline \multirow{4}{*}{$\begin{array}{l}\text { Educational } \\
\text { status }\end{array}$} & No education & $43.3 \pm 9.5$ & 6.175 & 0.001 \\
\hline & Primary & $48.9 \pm 18.9$ & & \\
\hline & Secondary & $63.9 \pm 17.8$ & & \\
\hline & Tertiary & $57.9 \pm 16.4$ & & \\
\hline \multirow[t]{3}{*}{ Social class } & White collar & $56.4 \pm 15.6$ & 2.582 & 0.079 \\
\hline & Blue collar & $66.8 \pm 19.4$ & & \\
\hline & Self employed & $58.9 \pm 20.3$ & & \\
\hline \multirow{3}{*}{$\begin{array}{l}\text { Income } \\
\text { group }\end{array}$} & Low income & $60.0 \pm 18.7$ & 0.905 & 0.407 \\
\hline & Middle income & $56.3 \pm 16.7$ & & \\
\hline & High income & $59.8 \pm 15.5$ & & \\
\hline \multirow[t]{2}{*}{ Numbness } & Present & $49.2 \pm 15.4$ & -3.213 & 0.002 \\
\hline & Absent & $59.3 \pm 17.3$ & & \\
\hline \multirow[t]{2}{*}{ Paraesthesia } & Present & $57.5 \pm 19.9$ & 0.043 & 0.966 \\
\hline & Absent & $57.3 \pm 17.0$ & & \\
\hline \multirow{2}{*}{$\begin{array}{l}\text { Lower limb } \\
\text { weakness }\end{array}$} & Present & $55.8 \pm 18.2$ & -0.633 & 0.528 \\
\hline & Absent & $57.8 \pm 17.2$ & & \\
\hline \multirow[t]{5}{*}{ Disability } & $\begin{array}{l}\text { Minimal } \\
\text { disability }\end{array}$ & $75.8 \pm 2.1$ & 35.323 & 0.000 \\
\hline & $\begin{array}{l}\text { Moderate } \\
\text { disability }\end{array}$ & $76.2 \pm 11.7$ & & \\
\hline & Severe disability & $57.9 \pm 15.1$ & & \\
\hline & Crippled & $46.8 \pm 10.1$ & & \\
\hline & Bedridden & $27.2 \pm 0.0$ & & \\
\hline
\end{tabular}

Respondents $(\mathrm{p}<0.0001)$ in the $50-59$ years age group had the lowest TQOL score. Respondents that were Yoruba ( $p$ $<0.0001$ ), who did not present with numbness in the lower limb $(\mathrm{p}=0.002)$, had significantly higher TQOL scores. The TQOL scores were significantly different among respondents of different educational status $(p=0.001)$, with respondents who did not have any formal education having the lowest TQOL scores. As the level of disability $(p<0.0001)$ and the duration of LBP $(p=0.027)$ increased, the TQOL score decreased.

\section{Pain intensity at different times and HRQOL summary scores}

The relationship between LBP intensity at different times and HRQOL summary scores are presented in table 6. As the pain intensity increased, the HRQOL summary scores decreased. The worst pain intensity had significantly higher correlation ( $r=-0.333$ to -0.427 ) with HRQOL summary scores.

Table 6. Relationship between pain intensity at different times and HRQOL summary scores

\begin{tabular}{llll}
\hline $\begin{array}{l}\text { HRQOL } \\
\text { summary } \\
\text { scores }\end{array}$ & QVAS subscale & PPMC (r) & P-value \\
\hline MCS & Present VAS & -0.112 & \\
& Average VAS & -0.265 & 0.133 \\
& Best VAS & -0.260 & 0.000 \\
& Worst VAS & -0.333 & 0.000 \\
PCS & Present & -0.280 & 0.000 \\
& Average & -0.303 & 0.000 \\
& Best & -0.248 & 0.000 \\
& Worst & -0.412 & 0.001 \\
TQOL & Present & -0.213 & 0.000 \\
& Average & -0.305 & 0.004 \\
& Best & -0.274 & 0.000 \\
& Worst & -0.427 & 0.000 \\
\hline
\end{tabular}

\section{Multivariate Analyses}

Table 7 shows the results of the multivariate analysis relating PCS score to predictor variables. Being a female ( $p$ $=0.024)$, a Yoruba $(\mathrm{p}<0.0001)$ and not having numbness in the lower limbs $(\mathrm{p}=0.014)$ were significant positive predictors of PCS score. Increasing level of disability $(\mathrm{p}<0.0001)$, LBP duration $(\mathrm{p}=0,002)$, age $(\mathrm{p}$ $=0.043)$ and worst LBP intensity $(p<0.0001)$ were significant negative predictors of PCS score.

Table 8 shows the results of the multivariate analysis relating MCS score to predictor variables. Being a Yoruba $(p=0.006)$, not having numbness in the lower $\operatorname{limb}(\mathrm{p}=0.002)$, being in the blue collar social class $(\mathrm{p}=$ $0.038)$, and in the high income group ( $p=0.029)$ were significant positive predictors of MCS score. Increasing level of disability ( $p<0.0001$ ) was a significant negative predictor of MCS score. Table 9 shows the results of the multivariate analysis relating TQOL score to predictor variables. Being a female $(p=0.011)$, a Yoruba $(p<$ 
$0.0001)$, and not having numbness in the lower limb ( $\mathrm{p}=$ 0.043 ) were significant positive predictors of TQOL score. Increasing age $(\mathrm{p}=0.005)$, increasing pain intensity $(\mathrm{p}=$ 0.038 ), and increasing level of disability $(\mathrm{p}<0.0001)$ were significant negative predictors of TQOL score.

Table 7. Multiple regression relating PCS score to predictor values

\begin{tabular}{lllll}
\hline PCS & Beta & P-value & Lower CI & Upper CI \\
\hline Constant & & 0.000 & 87.505 & 130.461 \\
Gender of & .146 & $.024 *$ & .677 & 9.591 \\
respondent & & & & \\
Age group & .130 & $.043^{*}$ & .006 & .355 \\
Tribal group & -.243 & $.000^{*}$ & -23.594 & -7.947 \\
Educational status & -.046 & .481 & -3.385 & 1.603 \\
Presence of & .172 & $.014 *$ & 1.453 & 12.762 \\
numbness & & & & \\
Levels of & -.497 & $.000^{*}$ & -14.182 & -8.531 \\
disability & & & & \\
Worst pain & -.281 & $.000^{*}$ & -3.932 & -1.511 \\
intensity & & & & \\
Duration of LBP & -.194 & $.002 *$ & -11.373 & -2.561 \\
\hline
\end{tabular}

Table 8. Multiple regression relating MCS score to predictor variables

\begin{tabular}{lllll}
\hline MCS & Beta & P-value & $\begin{array}{l}\text { Lower } \\
\text { CI }\end{array}$ & $\begin{array}{l}\text { Upper } \\
\text { CI }\end{array}$ \\
\hline Constant & & 0.000 & 45.403 & 110.463 \\
Age group & 0.105 & 0.168 & -0.771 & 4.374 \\
Tribal group & -0.203 & $0.006^{*}$ & -25.362 & -4.275 \\
Educational Status & 0.126 & 0.172 & -1.276 & 7.067 \\
Presence of & 0.231 & $0.002 *$ & 3.861 & 17.179 \\
numbness & & & & \\
Level of disability & -0.597 & $0.000^{*}$ & -22.082 & -12.058 \\
Worst pain intensity & 0.072 & 0.401 & -0.941 & 2.334 \\
Social class & 0.202 & $0.038^{*}$ & 0.253 & 8.441 \\
Income group & 0.166 & $0.029 *$ & 0.428 & 7.668 \\
\hline
\end{tabular}

Table 9. Multiple regression relating TQOL score to predictor variables

\begin{tabular}{lclll}
\hline TQOL & Beta & P-value & $\begin{array}{l}\text { Lower } \\
\text { CI }\end{array}$ & $\begin{array}{l}\text { Upper } \\
\text { CI }\end{array}$ \\
\hline Constant & & .000 & 63.206 & 115.102 \\
Age group & .209 & $.005^{*}$ & .961 & 5.281 \\
Tribal group & -.237 & $.000^{*}$ & -21.459 & -6.253 \\
Educational status & .017 & .852 & -3.325 & 4.017 \\
Presence of numbness & .156 & $.043^{*}$ & .215 & 12.666 \\
Levels of disability & -.610 & $.000^{*}$ & -16.074 & -10.144 \\
Worst pain intensity & -.148 & $.038^{*}$ & -2.587 & -.077 \\
Social class & .133 & .126 & -.746 & 5.971 \\
Gender of respondent & .203 & $.011^{*}$ & 1.603 & 12.099 \\
Duration of LBP & -.102 & .127 & -7.929 & 1.003 \\
\hline
\end{tabular}

* significant at $\mathrm{P}<0.05$

\section{DISCUSSION}

Non-specific LBP is rarely fatal but greatly affects the functional status of patients. Some studies have reported the effects of LBP on HRQOL in Caucasian and Asian populations (Horng et al, 2005; Patrick et al. 1995; Nickel et al. 2001). The result of this study is consistent with previous reports (Coste et al, 2004, Waddell, 1992) that revealed that LBP causes activity limitation and participation restriction. In this study, the impact of LBP on the summary measures of the SF 36, while adjusting for socio-demographic and clinical characteristics of LBP patients were investigated. The data obtained provided information on HRQOL across a range of domains among individuals receiving treatment for LBP in a tertiary health centre.

\section{LBP Impairment, Disability and HRQOL}

In this study, the mean PCS scores $(52.92 \pm 18.81)$ (which consist of the following domains: physical functioning, rolephysical, bodily pain and general health) were significantly lower than the MCS scores $(61.84 \pm 19.44)$ (which consist of the following domains - vitality, social functioning, roleemotional and mental health). Hence, we may conclude that LBP affects the physical health components of the patients more than the mental health component. This is in concord with the results of other studies (Patrick et al, 1995; SuarezAlmazor et al, 2000) that revealed bodily pain (a domain component of PCS) as the most responsive to change in patients with LBP. Also, this study shows that the HRQOL of LBP patients worsen with increasing pain severity and disability. This inverse relationship has been reported in other studies on the Caucasian and Asian populations (Kovacs et al, 2004, Horng et al, 2005).

\section{Predictors of HRQOL}

The multiple regression analysis revealed that an LBP patient who belongs to the blue collar social group, is a Yoruba, a high income earner, does not present with numbness in the lower limbs and does not have increasing level of disability would have a better mental component of HRQOL than an LBP patient who does not have these characteristics. An LBP patient who is female and a Yoruba, who does not have numbness in the lower limbs, has a level of disability greater than $40 \%$ (moderate disability), and pain intensity less than VAS of 7 , with duration of pain less than a year, will have a better physical component of HRQOL than an LBP patient who does not 
have these characteristics. Also, an LBP patient who is female, young (<49years), a Yoruba, who does not have numbness in the lower limbs, and without increasing level of disability and pain intensity will have a better overall HRQOL than an LBP patient who does not have these characteristics. The result of this study has again reemphasized the effects of socio-demographic variables on the outcome of LBP. Some studies (Picavet et al, 2002; Nyland and Grimmer, 2003; Webb et al, 2003; Steenstra et al, 2001) have shown that increasing age and being of the female gender are factors that predispose people to LBP and subsequent disability. This study has shown that increasing disability correlates significantly with decrease in HRQOL; hence, it is expected that being a female should worsen the HRQOL of LBP patients. But this study shows that female LBP patients are in fact likely to have a better health-related quality of life than male LBP patients. This might be a function of the way female patients respond to pain and disability, as male patients are said to catastrophize more than female patients (Picavet et al, 2002).

This study was carried out in southwestern Nigeria, a region dominated by the Yoruba. They accounted for $92 \%$ of the study population and this may explain the reason why being a Yoruba was a false predictor of HRQOL. Numbness in the lower limbs is a symptom that predicts a poor HRQOL. But Horng et al (2005) reported that the presence of lumbosacral radiculopathy correlates significantly with poor HRQOL. This may not necessarily be contradictory as numbness in the lower limbs may be a consequence of lumbosacral radiculopathy. The increasing incidence of disability and pain intensity in patients with LBP is a major predictor of poor HRQOL, which has been corroborated by several studies (Horng et al, 2005; Kovacs et al, 2004; Patrick et al, 1995).

The data from this study may be subject to Berksonian bias, as the respondents were all LBP patients who presented in the hospital with specific complaints. In order to make generalizable conclusions, a population-based study using a probability sampling technique will be recommended to survey the HRQOL of LBP patients at other places apart from the hospital. This may give a more objective description of their HRQOL. Cross-cultural content validity of the SF-36 questionnaire was assumed in this study. This presents a major limitation when comparing the concept of quality of life in different cultures, as the respondents' understanding of the questions might vary. This bias was minimized by ensuring that the interviewers were well-trained in the administration of the questionnaire, and that it was translated into the local language of the study location, with forward and backward translation.

Nevertheless, this study provides evidence for a model (Waddell, 1992) that links patients' status with regard to biology, symptoms, and functionality (HRQOL) and, by implication, may prove useful in guiding follow-up of patients with LBP. Disability prevention or reduction is the only modifiable overall predictor of HRQOL in LBP patients and this must be addressed to improve the HRQOL of these patients.

\section{CONCLUSION}

Evidence from this study shows that increasing age and level of disability adversely affected the HRQOL of LBP patients, more than just the pain (which affects the physical component of HRQOL more). Female patients had better HRQOL. The presence of numbness in the lower limb was the major symptom that significantly affected all the components of HRQOL adversely. The predictor of HRQOL in this population is not different from that in Asian and Caucasian populations.

\section{ACKNOWLEDGEMENTS}

The authors acknowledge the technical support received from Mrs. T.O. Olatunji, the Head of Department of Physiotherapy at the Federal Medical Centre Abeokuta, Ogun State, Nigeria. The authors also acknowledge all the patients who participated in the study for their cooperation. This project was fully sponsored by Mrs. Susannah Abimbola Ogunlana of the Samuel-Ogunlana Foundation.

\section{References}

Allan, D.B. and G. Waddell. 1989. An historical perspective on low back pain disability. Acta Orthop Scand Suppl 234: 1-23.

Andersson, G.B. 1999. Epidemiological features of chronic low back pain. Lancet 354 (9178): 581-5.

Bardage, C. and D.G. Isacson. 2001. Hypertension and healthrelated quality of life: An epidemiological study in Sweden. $J$ Clin Epidermol 54 (2): 172-81.

Coste, J., G. Lefrancois and F. Guillemin. 2004. Prognosis and quality of life in patients with acute low back pain: Insights from a comprehensive inception cohort study. Arthritis and Rheumatism 51:168-176.

Davidson, M. and J.A. Keating 2002. Comparison of five low back disability questionnaires reliability and responsiveness. Physical Therapy 82: 8-24.

Fairbank, J.C.T. and P.B. Pynscent. 2000. The Oswestry disability index. Spine 25(22): 2940-2953. 
Frymoyer, J.W. 1988.Back pain and sciatica. New England Journal of Medicine 318(5): 291-300.

Horng, Y.S., Y.H. Hwang, H.C. Wu, H.W. Liang, Y. Jang, F.C. Twu and J.D. Wang. 2005. Predicting health-related quality of life in patients with low back pain. Spine 30: 551.-5.

Kovacs, F.M., V. Abraira, J. Zamora and C. Fernandez. 2005. The Spanish back pain research network. The transition from acute to sub-acute chronic low back pain. A study based on determinants of quality of life and prediction of chronic disability. Spine 30: 1786-1792.

Nachemson, A.L. 1992. Newest knowledge of low back pain. A critical look. Clin Orthop 279: 8-20.

Nickel, R., U.T. Egle, P. Eysel, J.D. Rompe, J. Zollner and S.O. Hoffmann. 2001. Health-related quality of life and somatisation in patients with long-term low back pain: A prospective study with 109 patients. Spine 26: 2271-7.

Nyland L.J and K.A.. Grimmer. 2003. Is undergraduate physiotherapy study risk factor for low back pain? A prevalence study of LBP in physiotherapy students. BMC Musculoskeletal Disorders 4:22.

Patrick, D.L., R.A. Deyo, S.J. Atlas, D.E. Singer, A. Chapin and R.B. Keller. 1995. Assessing health-related quality of life in patients with sciatica. Spine 20: 1899-908.

Picavet H.S.J., J.W.S.Vleayan and J.S.A.G. Schouten 2002. Pain catastrophizing and kinesiophobia: Predictors of chronic low back pain. American Journal of Epidemiology 156(11): 10281034 .

Pincus, T., A.K. Burton, S. Vogel and A.P. Field. 2002. A systematic review of psychological factors as predictors of chronicity/disability in prospective cohorts of low back pain. Spine 27: E109-20.

Steentra, I.A., J.H. Verbeek, M.W. Heymans and P.M. Bongers. 2001. Prognostic factors for duration of sick leave in patients listed with acute low back pain: A systematic review of the literature. Occup Environ Med Rehabil 82 (6): 726-730.

Suarez-Almazor M.E, C. Kendall, J.A. Johnson, A.. Skeith and D. Vincent. 2000. Use of health status measures in patients with low back pain in clinical settings. Comparison of specific, generic and preference based instruments. Rheumatology (Oxford) 39(7): 783-90.

Testa, M.A. and D.C. Simonson, D.C. 1996. Assessment of quality of life outcomes. N. Eng J. Med 334 (13): 835-840.

Von Korff, M., R.A. Deyo, D. Cherkin and W. Barlow. 1993. Back pain in primary care: Outcomes at 1- year. Spine 18(7): 855-62.

Webb. R., T. Brammah, M. Lunt, M. Urwin, T. Alison and D. Symmons. 2003. Prevalence and predictors of intense, chronic and disabling neck and back pain in the UK general population. Spine 28 (11): 1195-202.

Waddell, G., D. Someville, I. Henderson and M. Newton. 1992. Objective clinical evaluation of physical impairment in chronic low back pain. Spine 17: 617-628.

Ware J. 2000. SF-36. Health survey update. Spine 25(24): 31303139 . 